Gut, 1979, 20, 609-615

Epidemiology

\title{
Diverticular disease of the large intestine in Northern Norway
}

\author{
T. J. EIDE ${ }^{1}$ AND HELGE STALSBERG \\ From the Institute of Medical Biology, University of Tromsø, Tromsø, Norway
}

SUMMARY In 280 unselected necropsies on patients over 20 years of age in Northern Norway, diverticular disease was present in $25 \%$ of the males and $43 \%$ of the females. The frequency of diverticular disease increased in both sexes by age. Both the frequency of diverticular disease and the average number of diverticula per case with diverticular disease were higher in females than in males in all age groups. The sigmoid was the most frequent site of diverticula in both sexes and for all ages, and the average number of diverticula per diverticulum-bearing segment was also highest in the sigmoid for all ages and in both sexes. The average number of diverticula in the sigmoid of affected individuals increased with age and with the number of segments involved. Diverticular disease was not associated with adenomas of the large intestine or with malignant or benign neoplasms elsewhere in the body or with any of the common diseases thought to be related to a Western type of diet, except with cerebrovascular disease.

Geographical variation in the frequency of diverticular disease of the large intestine appears to be similar to that of colorectal carcinoma. Both conditions are thought to be related to a Western type of diet, and it has been suggested that the aetiological factors of both may be the same or closely related (Burkitt, 1971). However, epidemiological investigations on diverticular disease have been few, and data from more populations are needed to study the association between diverticular and neoplastic disease. The relationship between diverticular disease and other conditions thought to be of dietary origin, such as atherosclerosis, chronic gallbladder disease, and obesity also needs further investigation.

This necropsy study has been performed in a Norwegian coastal population at 70 degrees north. It is part of a collaborative project on populations in Northern Europe having different incidence of colorectal carcinoma. The primary purpose of the project, which is coordinated by the International Agency for the Research on Cancer (IARC), is to study the occurrence of pathological lesions in the large intestine that may either be premalignant

\footnotetext{
${ }^{1}$ Address for reprints: Dr Tor J. Eide, Department of Pathology, University Hospital, 9012 Tromsø, Norway.

Received for publication 11 January 1979
}

precursors or lesions otherwise related to the development of colorectal carcinoma.

\section{Methods}

MATERIAL

During a period of 22 months from 1974 to 1976 the necropsy staff at the University Hospital in Tromsø were asked to collect the large intestine from all necropsies, except in patients under 20 years of age, those in whom more than 72 hours has passed from the time of death to necropsy, and those who had undergone surgical resection of the large intestine. About 130 cases had to be excluded because the necropsy staff failed to adhere consistently to the procedure requested, leaving 171 male and 109 female cases for study. When causes of death were grouped as primary cancer of the digestive system, other cancers, coronary and cerebrovascular diseases, violent death, and other causes, the distribution in the present study material was similar to that in the total necropsy material of the department in the general population of the region (Norway, Central Bureau of Statistics, 1974b).

\section{PROCEDURE}

With the large intestine in situ, the right and left flexures, the proximal end of the sigmoid colon, and 
the rectosigmoid junction were marked with safety pins.

The proximal end of the sigmoid colon was defined by the point where the colon passes the inlet of the true pelvis, at the upper border of the $S_{1}$ segment of os sacrum. The rectosigmoid junction was defined by the point where the bowel passes the upper border of the $S_{3}$ segment. The large intestine was removed in toto and opened at the taenia libera. The specimen was pinned out on a $70 \times 60 \mathrm{~cm}$ cork plate and immersed in $4 \%$ neutral buffered formalin for at least two days.

The mucosa was examined after fixation under an illuminating magnifying lens $(\times 2)$, and all diverticula in each segment (caecum; ascending; transverse; descending and sigmoid colon and rectum) were counted. All lesions with a distinct orifice visible on the mucosal surface were regarded as diverticula irrespective of the presence of corresponding serosal protrusions. This was done to avoid underestimating the number of diverticula, as many of them were not visible from the serosal side because of small size, retraction of the diverticula into the muscular wall, or embedding in massive peritoneal fat.

The presence of melanosis was recorded, and all polyps $1 \mathrm{~mm}$ or larger were taken out for histological examination and classified according to the WHO classification (Morson and Sobin, 1976). A more detailed description of the analysis of polyps is given elsewhere (Eide and Stalsberg, 1978).

\section{Results}

Diverticular disease of the large intestine, defined as the presence of one or more diverticula, was found in 90 of 280 cases as shown in Table 1 . The prevalence rate was higher in females than in males in all age groups. Statistically, the difference reached the $5 \%$ level of significance only in the 65-74 years age group. For both sexes there was a significant increase in prevalence by age (females, $\chi^{2}$ for trend $=4.89$, $\mathrm{P}<0.05$; males, $\chi^{2}$ for trend $\left.=4.43, \mathrm{P}<0.05\right)$. In both sexes, however, the major difference was between patients under and over 55 years of age.

The sigmoid colon was the most frequent site of diverticula in both sexes (Table 2). Of all cases with diverticular disease, $89 \%$ had diverticula in the sigmoid colon, and $40 \%$ had diverticula in the sigmoid only. Although diverticula in the descending colon were present in $49 \%$ of all cases with diverticular disease, only two cases had diverticula confined only to this segment. Five males and one female had diverticula only in the caecum or in the ascending colon. All patients with diverticula in the transverse colon and in the rectum also had diverticula in the sigmoid or descending colon, or both. Two male and
Table 1 Prevalence of diverticular disease by sex and age

\begin{tabular}{lccl}
\hline $\begin{array}{l}\text { Age } \\
(y r)\end{array}$ & $\begin{array}{l}\text { Intestines } \\
\text { examined }\end{array}$ & $\begin{array}{l}\text { Intestines with } \\
\text { diverticular } \\
\text { disease }\end{array}$ & Rate \\
\hline Males & & & \\
$20-54$ & 33 & 3 & 0.09 \\
$55-64$ & 36 & 11 & 0.31 \\
$65-74$ & 55 & 13 & 0.24 \\
$75+$ & 47 & 16 & 0.34 \\
Total & 171 & 43 & 0.25 \\
Females & & & \\
$20-54$ & 19 & 4 & 0.21 \\
$55-64$ & 13 & 5 & 0.38 \\
$65-74$ & 28 & 13 & 0.46 \\
$75+$ & 49 & 25 & 0.51 \\
Total & 109 & 47 & 0.43 \\
\hline
\end{tabular}

Täbie 2 Number of cases with diverticular disease in single and multiple intestinal segments

\begin{tabular}{lrrr}
\hline & Males & Females & Total \\
\hline Single segment & & & \\
$\quad$ Caecum & 3 & 0 & 3 \\
Ascending & 2 & 1 & 3 \\
Descending & 1 & 1 & 2 \\
$\quad$ Sigmoid & 15 & 21 & 36 \\
Multiple segments & 1 & 0 & 1 \\
$\quad$ Ascending and descending & 1 & 0 & 1 \\
$\quad$ Transverse and descending & 12 & 15 & 27 \\
$\quad$ Sigmoid and descending & 1 & 1 & 2 \\
Sigmoid and transverse & 1 & 1 & 2 \\
$\quad$ Sigmoid and ascending & 0 & 2 & 2 \\
$\quad$ Sigmoid, descending and rectum & 4 & 3 & 7 \\
$\quad$ Sigmoid, descending and transverse & & & \\
Sigmoid, descending, transverse and & 2 & 2 & 4 \\
$\quad$ ascending & 43 & 47 & 90 \\
All cases & & & \\
\hline
\end{tabular}

two female cases had advanced diverticular disease with diverticula in all segments of the large intestine except in the caecum and rectum.

Tables $3 a$ and $3 b$ show the frequency of diverticular disease in each segment by age for males and females respectively. There was an increase in the frequency with age in sigmoid and descending segments in both sexes; in the sigmoid and descending colon the frequencies of diverticular disease were also higher in females than in males in all age groups. Diverticula in the caecum were present in only three males before the age of 65 years. In other segments there was no obvious trend of variation with either age or sex. The prevalence rates for the sigmoid colon were higher than those for any other segment in both sexes at all ages.

The average total number of diverticula per case with diverticular disease was higher in females than in males in all age groups (Table 4). The average number of diverticula per diverticulum-bearing segments was highest in the sigmoid colon for all ages in both sexes, and in the sigmoid this figure increased markedly with age. In all other segments, 
Table 3a Number of cases with diverticular disease in each intestinal segment by age; males

\begin{tabular}{|c|c|c|c|c|c|c|}
\hline & \multicolumn{6}{|c|}{ Age $(y r)$} \\
\hline & $20-54$ & $55-64$ & $65-74$ & & $75+$ & All ages \\
\hline \multicolumn{7}{|l|}{ Segment } \\
\hline Caecum & 1 & 2 & - & & - & 3 \\
\hline Rate & 0.03 & 0.06 & - & & - & 0.02 \\
\hline Ascending & 1 & 1 & 2 & & 2 & 6 \\
\hline Rate & 0.03 & 0.03 & 0.04 & & 0.04 & 0.04 \\
\hline Transverse & 1 & 2 & 2 & & 3 & 9 \\
\hline Rate & 0.03 & 0.06 & 0.04 & & 0.06 & 0.05 \\
\hline Descending & 1 & 4 & 7 & & 9 & 21 \\
\hline Rate & 0.03 & $0 \cdot 11$ & 0.13 & & $0 \cdot 19$ & 0.12 \\
\hline Sigmoid & 2 & 8 & 11 & & 14 & 35 \\
\hline Rate & 0.06 & 0.22 & 0.20 & 、 & 0.30 & 0.20 \\
\hline Rectum & - & - & - & 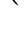 & - & 0 \\
\hline Rate & - & - & - & & - & - \\
\hline Total no. of cases examined & 33 & 36 & 55 & & 47 & 171 \\
\hline
\end{tabular}

Table 3b Number of cases with diverticular disease in each intestinal segment by age; females

\begin{tabular}{|c|c|c|c|c|c|}
\hline & \multicolumn{5}{|c|}{ Age $(y r)$} \\
\hline & $20-54$ & $55-64$ & $65-74$ & $75+$ & All ages \\
\hline \multicolumn{6}{|l|}{ Segment } \\
\hline Caecum & - & - & - & - & 0 \\
\hline Rate & - & - & - & - & - \\
\hline Ascending & - & - & 2 & 2 & 4 \\
\hline Rate & - & - & 0.07 & 0.04 & 0.04 \\
\hline Transverse & - & 1 & 2 & 3 & 6 \\
\hline Rate & - & 0.08 & 0.07 & 0.06 & 0.06 \\
\hline Descending & 1 & 2 & 6 & 14 & 23 \\
\hline Rate & 0.05 & 0.15 & 0.21 & 0.29 & 0.21 \\
\hline Sigmoid & 4 & 5 & 13 & 23 & $45^{24}$ \\
\hline Rate & 0.21 & 0.38 & 0.46 & 0.47 & 0.41 \\
\hline Rectum & - & - & - & 2 & 2 \\
\hline Rate & - & - & - & 0.04 & 0.02 \\
\hline Total no. of cases examined & 19 & 13 & 28 & 49 & 109 \\
\hline
\end{tabular}

Table 4 Average number of diverticula per diverticulum-bearing segment by segment, sex, and age

\begin{tabular}{|c|c|c|c|c|c|c|c|c|}
\hline & \multicolumn{8}{|c|}{ Age $(y r)$} \\
\hline & \multicolumn{2}{|l|}{$20-54$} & \multicolumn{2}{|l|}{$55-64$} & \multicolumn{2}{|l|}{$65-74$} & \multicolumn{2}{|l|}{$75+$} \\
\hline & Males & Females & Males & Females & Males & Females & Males & Females \\
\hline Caecum & $2 \cdot 0$ & - & $5 \cdot 0$ & - & - & - & - & - \\
\hline Ascending & $4 \cdot 0$ & - & $2 \cdot 0$ & - & $2 \cdot 5$ & $5 \cdot 5$ & 1.0 & 3.0 \\
\hline Transverse & $3 \cdot 0$ & 一 & $2 \cdot 0$ & $1 \cdot 0$ & $1 \cdot 0$ & $11 \cdot 0$ & $2 \cdot 3$ & 3.7 \\
\hline Descending & $3 \cdot 0$ & $8 \cdot 0$ & $7 \cdot 8$ & $9 \cdot 5$ & $7 \cdot 6$ & $12 \cdot 3$ & $9 \cdot 3$ & 6.6 \\
\hline Sigmoid & $7 \cdot 0$ & $9 \cdot 0$ & $13 \cdot 5$ & $12 \cdot 8$ & $13 \cdot 5$ & $23 \cdot 5$ & $15 \cdot 6$ & $26 \cdot 4$ \\
\hline Rectum & - & - & - & - & - & - & - & $5 \cdot 5$ \\
\hline Total large intestine & $8 \cdot 7$ & $11 \cdot 0$ & $14 \cdot 1$ & $16 \cdot 8$ & $16 \cdot 0$ & $31 \cdot 7$ & $19 \cdot 4$ & $29 \cdot 1$ \\
\hline
\end{tabular}

the average number of diverticula per diverticulumbearing segment showed little change with age. After 65 years in females and after 75 years in males diverticula in multiple segments were more frequent than in single segments.

Figure 1 shows the average number of diverticula in the sigmoid colon as related to the presence or absence of diverticula in other segments. Evidently, the more other segments that were involved with diverticular disease, the higher was the average number of diverticula in the sigmoid. The trend was present in both sexes and at ages both under and over 65 years.

Table 5 relates the presence of diverticular disease to the presence of adenomas in the large intestine. The rates of diverticular disease were very similar in cases with adenomas and in those without, and these data gave no evidence for an association between the two types of lesion.

Figure 2 compares the distribution of diverticula 


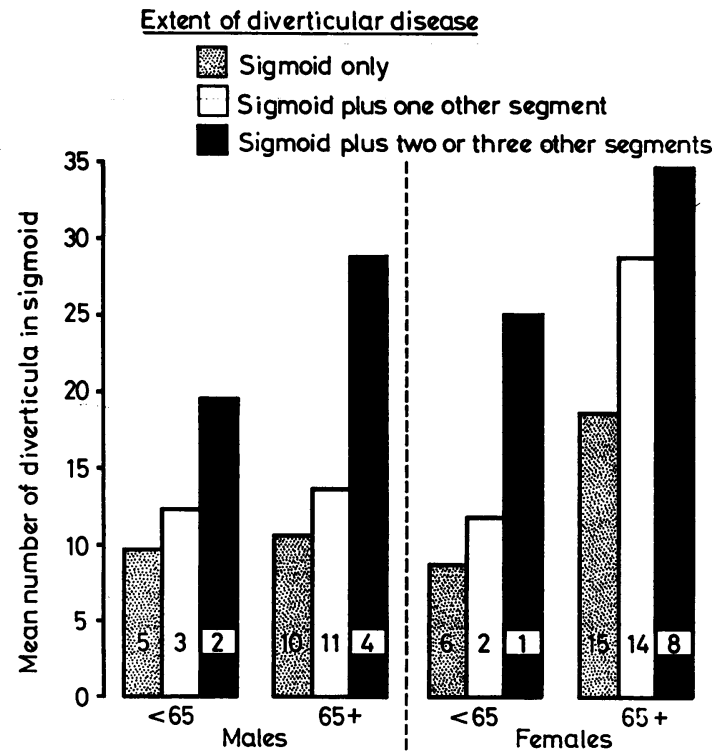

Fig. 1 Mean number of diverticula in sigmoid colon in cases with diverticula in sigmoid only and in sigmoid plus one or more segments, by sex and age. Figures within columns indicate the number of cases.

and the distribution of adenomas within the large intestine. In the upper diagrams, the prevalence of adenoma, single or multiple, in each segment is compared with the prevalence of diverticular disease in each segment. In the lower diagrams, the mean numbers of adenoma and diverticula per centimetre segmental length are compared. By both ways of analysis, the sigmoid stood out as a very prominent site of predilection for diverticular disease, in contrast with the more even distribution of adenomas among the segments.

Hyperplastic polyps were diagnosed in 55 cases, and melanosis in 23 cases. None of these conditions was found to be statistically associated with the occurrence of diverticular disease. Diverticular disease was not found to be statistically associated with the presence of any of the following diseases, for which the number of cases in each group is given in parentheses: coronary heart disease (147), diabetes mellitus (21), chronic gallbladder disease (42),
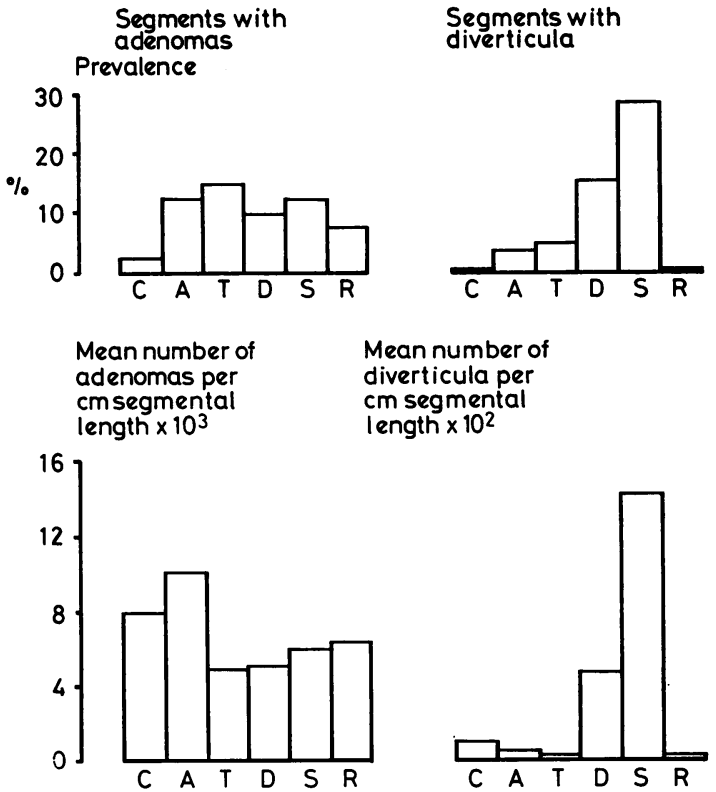

Fig. 2 Comparison of the distribution of adenomas and diverticular disease within the large intestine. Above: prevalence of adenomas and diverticular disease by intestinal segment. Below: mean number of adenomas and diverticula per $\mathrm{cm}$ segmental length, by intestinal segment. C: caecum. A: ascending. T: transverse. $D$ : descending. $S$ : sigmoid. $R$ : rectum.

malignant neoplasms (68), or benign neoplasms other than adenomas of the large intestine (51). Cases with cerebrovascular disease (59) had a significantly higher frequency of diverticular disease than in the total material $\left(\chi^{2}=7.17, P<0.01\right)$. When grouped by sex and age, the difference was significant only in males over the age of 65 years $\left(\chi^{2}=5 \cdot 13, \mathrm{P}<0.025\right)$, but the trend remained also in the other groups (Table 6).

The mean ponderal index (body height in $\mathrm{cm}$ divided by the square root of body weight in $\mathrm{kg}$ ) (Wilson, 1969) (Table 7) was slightly decreased in cases with diverticular disease for all age groups, weakly indicating a possible relationship between obesity and diverticular disease. However, the

Table 5 Prevalence rates of diverticular disease related to presence of colorectal adenomas by sex and age

\begin{tabular}{|c|c|c|c|c|c|c|}
\hline \multirow[t]{3}{*}{ Cases } & \multicolumn{3}{|l|}{ Males } & \multicolumn{3}{|l|}{ Females } \\
\hline & \multirow[t]{2}{*}{ No. of cases } & \multicolumn{2}{|c|}{$\operatorname{Age}(y r)$} & \multirow[t]{2}{*}{ No. of cases } & \multicolumn{2}{|c|}{ Age $(y r)$} \\
\hline & & -64 & $65+$ & & -64 & $65+$ \\
\hline $\begin{array}{l}\text { With adenomas } \\
\text { Without adenomas }\end{array}$ & $\begin{array}{r}68 \\
103\end{array}$ & $\begin{array}{l}0.22 \\
0.20\end{array}$ & $\begin{array}{l}0.30 \\
0.27\end{array}$ & $\begin{array}{l}36 \\
73\end{array}$ & $\begin{array}{l}0.33 \\
0.26\end{array}$ & $\begin{array}{l}0.48 \\
0.50\end{array}$ \\
\hline
\end{tabular}


Table 6 Prevalence rates of diverticular disease related to presence of cerebrovascular disease by sex and age

\begin{tabular}{|c|c|c|c|c|c|c|}
\hline \multirow[t]{3}{*}{ Cases } & \multicolumn{3}{|l|}{ Males } & \multicolumn{3}{|l|}{ Females } \\
\hline & \multirow[t]{2}{*}{ No. of cases } & \multicolumn{2}{|c|}{ Age (yr) } & \multirow[t]{2}{*}{ No. of cases } & \multicolumn{2}{|c|}{ Age (yr) } \\
\hline & & -64 & $65+$ & & -64 & $65+$ \\
\hline $\begin{array}{l}\text { With cerebrovascular disease } \\
\text { Without cerebrovascular disease }\end{array}$ & $\begin{array}{r}32 \\
139\end{array}$ & $\begin{array}{l}0 \cdot 40 \\
0 \cdot 17\end{array}$ & $\begin{array}{l}0.50 \\
0.23\end{array}$ & $\begin{array}{l}27 \\
82\end{array}$ & $\begin{array}{l}0 \cdot 33 \\
0 \cdot 27\end{array}$ & $\begin{array}{l}0.57 \\
0.46\end{array}$ \\
\hline
\end{tabular}

Table 7 Mean ponderal index* in cases with and without diverticular disease

\begin{tabular}{|c|c|c|c|c|c|c|c|}
\hline \multirow[t]{2}{*}{ Cases } & \multicolumn{4}{|c|}{$\operatorname{Age}(y r)$} & \multicolumn{3}{|c|}{ All ages } \\
\hline & $20-54$ & $55-64$ & $65-74$ & $75+$ & & $S D$ & $n \dagger$ \\
\hline $\begin{array}{l}\text { With diverticular disease } \\
\text { Without diverticular disease }\end{array}$ & $\begin{array}{l}20 \cdot 8 \\
21 \cdot 0\end{array}$ & $\begin{array}{l}21 \cdot 1 \\
21 \cdot 2\end{array}$ & $\begin{array}{l}20 \cdot 6 \\
21 \cdot 3\end{array}$ & $\begin{array}{l}21 \cdot 1 \\
21 \cdot 2\end{array}$ & $\begin{array}{l}20 \cdot 9 \\
21 \cdot 2\end{array}$ & $\begin{array}{l}1.57 \\
2.20\end{array}$ & $\begin{array}{r}87 \\
185\end{array}$ \\
\hline
\end{tabular}

*Height in $\mathrm{cm}$ divided by square root of weight in $\mathrm{kg}$.

$t_{n}$ : number of cases (eight missing observations).

$t$ test for difference between means, all ages, $t=1.01, \mathrm{P}>0.05$.

association was not statistically significant $(t=1 \cdot 01$, $\mathrm{P}>0.05)$.

\section{Discussion}

The distribution of underlying causes of death in major diagnostic categories was similar in the study material, in the total necropsy population, and in the general population at death. Thus, although a relatively large number of the cases coming to necropsy had to be excluded for various reasons, we have no reason to believe that this has introduced any systematic bias with regard to the occurrence of diverticular disease.

In clinical studies, colonic diverticulitis has been found to be far more frequent among Europeans than among other races in studies performed in Scotland, Nigeria, Singapore, and Fiji (Kyle et al., 1967). In a comparative study of consecutive barium enema examinations, Køhler (1963) found that diverticular disease was diagnosed three times more frequently in Sweden than in Finland and suggested that the difference might partly be due to racial predisposition. However, a strong argument for the importance of environmental factors was given by Stemmermann and Yatani (1973), who showed that diverticular disease is common among Japanese living in Hawaii, although it is rarely seen among Japanese living in Japan (Sato et al., 1976). Also Levy et al. (1977) in a radiological study in Israel have emphasised the environmental aetiology of diverticular disease, as they found that colonic diverticulosis in Jews born in Western Europe and America was more than four times higher than in oriental Jews. Within the city of Edinburgh, diverticular disease was found to be more common in parts of the city where the social status was generally low (Eastwood et al., 1977).

Prospective necropsy studies are few and have mostly been performed in areas which have a high risk of diverticular disease and in which a large part of the food is usually processed and refined. In persons over 50 years of age, the prevalence of diverticular disease has been reported to be $54 \%$ in Hawaiian Japanese (Stemmermann and Yatani, 1973), $48 \%$ in an Australian series (Hughes, 1969), and $42 \%$ in a British series (Parks, 1968). The somewhat lower prevalence of $35 \%$ over the age of 50 years in this study may possibly be related to the fact that $53 \%$ of the population in Troms county are living in rural areas, and $16 \%$ derive their main income from fishing and agriculture (Norway, Central Bureau of Statistics, 1975).

The incidence of cancer of the colon and rectum in the total population and the prevalence of diverticular disease at necropsy have been compared in Table 8 for the few areas from which data on both are available. The frequencies of colon and rectum cancer and diverticular disease follow a similar international trend, except in Malta where the risk of colorectal cancer is low but the prevalence of diverticular disease is fairly high in both sexes (Stemmermann and Yatani, 1973; Podestà and Pace, 1975; Sato et al., 1976; Waterhouse et al., 1976). The variations among the four populations are greater for diverticular disease than for cancer.

In studies on individual patients within populations, Køhler (1963) found no higher frequency of carcinoma in cases with diverticular disease than in those without. In the present study there is no higher frequency of adenomas in cases with diverticular disease than in those without, which is consistent with the findings of Stemmermann and Yatani (1973). 
Table 8 Incidence of cancer of colon and rectum in living population and prevalence of diverticular disease in necropsy studies in different areas

\begin{tabular}{|c|c|c|c|c|c|c|c|}
\hline & \multicolumn{4}{|c|}{ Annual cancer incidence per $100000^{*}$} & \multicolumn{3}{|c|}{ Prevalence of diverticular disease $(\%)$} \\
\hline & \multicolumn{2}{|l|}{ Males } & \multicolumn{2}{|c|}{ Females } & \multirow[t]{2}{*}{ Males } & \multirow[t]{2}{*}{ Females } & \multirow[t]{2}{*}{$\operatorname{Age}(y r)$} \\
\hline & Colon & Rectum & Colon & Rectum & & & \\
\hline $\begin{array}{l}\text { Hawaii, Japanese } \\
\text { (Stemmermann and Yatani, 1973; } \\
\text { Waterhouse et al., 1976) }\end{array}$ & $22 \cdot 4$ & $16 \cdot 3$ & $18 \cdot 8$ & $10 \cdot 1$ & 57 & 51 & $50+$ \\
\hline Tromsø, Norway $\dagger$ & $9 \cdot 1$ & $6 \cdot 6$ & $11 \cdot 8$ & $5 \cdot 4$ & 27 & 47 & $50+$ \\
\hline $\begin{array}{l}\text { Malta } \\
\text { (Podestà and Pace, 1975; Waterhouse } \\
\text { et al., 1976) }\end{array}$ & $7 \cdot 0$ & $5 \cdot 8$ & $5 \cdot 3$ & $3 \cdot 4$ & 27 & 16 & All ages \\
\hline $\begin{array}{l}\text { Miyagi, Japan } \\
\text { (Sato et al., 1976; Waterhouse et al., } \\
\text { 1976) }\end{array}$ & $5 \cdot 6$ & $6 \cdot 8$ & $5 \cdot 4$ & $5 \cdot 0$ & 1 & 1 & $50+$ \\
\hline
\end{tabular}

* Age standardised to world population.

†Incidence figures given by the Cancer Registry of Norway.

The present study also shows that there is no similarity in the distribution of adenomas and diverticula within the large intestine. Thus, although there is some association between diverticular and neoplastic disease of the large intestine when different populations are compared, the occurrence of the two types of lesion within a homogeneous population seems to be mutually independent.

Obesity and diverticular disease are both common in industrialised countries of the Western world, where the consumption of refined carbohydrates is higher and the dietary fibre content is lower than in most other areas, which may indicate that both obesity and diverticular disease have common causative factors. By grading the amount of fat attached to the colon at necropsy, Parks (1968) found on the average more fat with colons with diverticula than in those without. Possibly, however, the amount of pericolic fat may be more directly related to diverticular disease and may not be a useful index of general obesity. Measuring the subcutaneous fat at the umbilicus, Hughes (1969) found no significant association between diverticular disease and obesity at necropsy, which agrees with our analysis of the ponderal index.

The first studies on diverticular disease reported in this century showed a male predominance, but, in later years, several series have demonstrated a female predominance (Manousos et al., 1967), particularly in the older age groups (Køhler, 1963; Kyle et al., 1967). Although our results show higher rates for females than for males in all age groups, female predominance is most pronounced after the age of 65 years with diverticular disease. Our study also shows a larger average number of diverticula in females than in males with diverticular disease, mainly in the sigmoid colon. Thus, females are more inclined to develop left-sided diverticular disease than males, and they are also on the average more severely affected than males.

The more detailed analysis of the individual segments of the large intestine shows that both the female predominance and the increase in prevalence rates with age are largely associated with increasing numbers of diverticula in the sigmoid and descending colon. In the right and transverse colon, the prevalence of the diverticula seems to be rather independent of both sex and age, which may indicate that rightsided diverticular disease is a different disease entity.

The increase in prevalence of diverticular disease by age in our study is accompanied by an increase in the number of segments affected and in the number of diverticula in the sigmoid colon. The average number of diverticula in the sigmoid colon also increases with the number of segments affected. A reasonable explanation of these observations is that diverticular disease when present in the sigmoid colon generally progresses to other segments before the disease has come to a final stage in the sigmoid. This is in contrast with the view of Parks (1969) who, in a retrospective radiological study, found that the process tended to progress within those segments in which diverticula first appeared rather than spread to other segments.

\section{References}

Burkitt, D. P. (1971). Epidemiology of cancer of the colon and rectum. Cancer, 28, 3-13.

Eastwood, M. A., Sanderson, J., Pocock, S. J., and Mitchell, W. D. (1977). Variation in the incidence of diverticular disease within the city of Edinburgh. Gut, 18, 571-574.

Eide, T. J., and Stalsberg, H. (1978). Polyps of the large intestine in Northern Norway. Cancer, 42, 2839-2848.

Hughes, L. E. (1969). Postmortem survey of diverticular disease of the colon. Part I. Diverticulosis and diverticulitis. Gut, 10, 336-351.

Køhler, R. (1963). The incidence of colonic diverticulosis in 
Finland and Sweden. Acta Chirurgica Scandinavica, 126, 148-155.

Kyle, J., Adesola, A. O., Tinckler, L. F., and de Beaux, J. (1967). Incidence of diverticulitis. Scandinavian Journal of Gastroenterology, 2, 77-80.

Levy, N., Luboshitzki, R., Shiratzki, Y., and Ghivarello, M. (1977). Diverticulosis of the colon in Israel. Diseases of the Colon and Rectum, 20, 477-481.

Manousos, O. N., Truelove, S. C., and Lumsden, K. (1967). Prevalence of colonic diverticulosis in general population of Oxford area. British Medical Journal, 3, 762-763.

Morson, B. C., and Sobin, L. H. (1976). Histological Typing of Intestinal Tumours. WHO: Geneva.

Norway, Central Bureau of Statistics (1974a). Mortality Rates in Counties 1969-1972. Central Bureau of Statistics: Oslo.

Norway, Central Bureau of Statistics (1974b). Population by Age and Material Status. Central Bureau of Statistics: Oslo.

Norway, Central Bureau of Statistics (1975). Statistical Yearbook Central Bureau of Statistics: Oslo.
Parks, T. G. (1968). Postmortem studies on the colon with special references to diverticular disease. Proceedings of the Royal Society of Medicine, 61, 932-934.

Parks, T. G. (1969). Natural history of diverticular disease of the colon. A review of 521 cases. British Medical Journal, 4, 639-642.

Podestà, M. T., and Pace, J. L. (1975). Distribution of diverticula of the large intestine based on post mortem studies. International Surgery, 60, 395-396.

Sato, E., Ouchi, A., Sasano, N., and Ishidate, T. (1976). Polyps and diverticulosis of large bowel in autopsy population of Akita prefecture, compared with Miyagi. High risk for colorectal cancer in Japan. Cancer, 37, 13161321.

Stemmermann, G. N., and Yatani, R. (1973). Diverticulosis and polyps of the large intestine. Cancer, 31, 1260-1270.

Waterhouse, J., Muir, C., Correa, P., and Powell, J. (1976). Cancer Incidence in Five Continents. Vol. 3. IARC: Lyons.

Wilson, N. L. ed. (1969). Obesity. Davis: Philadelphia. 